\title{
Fuel Part and Mineral Part of the Thermoecological Cost
}

\author{
Jan Szargut \& Wojciech Stanek \\ Institute of Thermal Technology, Silesian University of Technology \\ 44100 Gliwice, Poland \\ E-mail: wojciech.stanek@polsl.pl
}

\begin{abstract}
The thermoecological cost, expressing the cumulative consumption of nonrenewable exergy per unit of the considered useful product, may be divided into the fuel part and the mineral part. The fuel part may be eliminated by the utilization of renewable exergy carriers. The mineral part cannot be eliminated. The depletion of mineral resources leads to the necessity of utilization of more and more lean natural resources. The equation system determining the fraction of the fuel part of thermoecological cost is formulated. Two numerical examples are included. The first one is a simple demonstration example. The second is detailed and relates to the Polish energy system.
\end{abstract}

Keywords: Resources of exergy; cumulative consumption; depletion of resources.

\section{Introduction}

The application of exergy in solving the optimization problems of thermal processes has been developed in the last decades in two directions. The first one called thermoeconomics aims at a maximum of economic profit, expressed in monetary units. One of the pioneers in that domain was Y. M. El-Sayed (El-Sayed, 1970a; 1970b). The second direction initiated by J. Szargut (Szargut, 1978; 1986; 1997) is based upon the concept of the thermoecological cost (TEC), expressing the cumulative exergy depletion of nonrenewable natural resources burdening the considered consumption product. The mentioned index is expressed in the units of energy-exergy, not in monetary units.

The depletion of nonrenewable natural resources is very dangerous for the future economy of humankind. The values of the TEC may be used for the selection of production technology and for the optimization of the design and operational parameters of the production installations (Szargut, 2004). The calculation of the TEC may be performed in the scope of the total globe or in the limits of some region or country. When considering only some country, the data characterizing export and import of the products and raw materials should be taken into account. The so far elaborated calculation methods take into account all the kinds of nonrenewable natural resources. However there exist a substantial difference between the fuel resources and the mineral resources. Fuel resources can be eliminated by the use of renewable natural exergy resources, for example, by the exergy of solar radiation or its secondary forms (wind, water from atmospheric falls, chemical exergy of plants). Mineral resources cannot be eliminated, because any renewable mineral resources do not exist. Therefore, the partition of the TEC into the fuel part $\mathrm{TEC}_{\mathrm{f}}$ and the mineral part $\mathrm{TEC}_{\mathrm{m}}$ is expedient.

\section{System of balance equations}

The total value of TEC of the products of every process equals to the sum of values of inflow exergy components
(Stanek, 2009). Hence, the balance equations may be used for the calculation of the values of TEC. The balance equations are mutually dependent if some useful product is applied as a raw material in another production process. Only in that case a system of balance equations should be formulated. In the case of ready consumption products the balance equations are mutually independent and can be used by means of a sequence method, beginning with the product and going back through all the production steps. The balance equations may be formulated according to the principles of life cycle assessment, LCA (Cornellisen, 2000). After the wear of the production installation, its solid components can be recycled for the use in building new production installations. That fact, according to the LCA, should be taken into account in the balance equation determining the TEC. The secondary materials obtained after the wear of the production installation can be treated similarly as the useful byproducts.

The calculation of the $\mathrm{TEC}_{\mathrm{f}}$ and $\mathrm{TEC}_{\mathrm{m}}$ can be made in two steps. In the first one the general form of the balance equations determining the total TEC has to be formulated in the form presented in (Stanek 2009, Szargut 1986). In the second step the balance equations may be formulated that contain the unknown fractions $z_{j}, z_{i}$ of the $\mathrm{TEC}_{\mathrm{f}}$ in the total value of TEC. The second equation system is independent from the first one.

Every balance equation determining the TEC contains on the outflow side the specific TEC value of the major product and the values characterizing the connected useful byproducts (Szargut, 1978). When calculating the TEC values, the secondary raw materials obtained after the dismantling of the worn installation should be taken into account in the outflow components, similarly as the byproducts.

The TEC of every useful byproduct should be expressed by the value of TEC of a major product fabricated in another process and replacing the considered byproduct. The replacement ratio between the byproduct and the replaced major product should be taken into account.

On the inflow side of the balance equation the TEC values of the used domestic raw materials and semifinished products 
are introduced, also the TEC values of the imported raw materials and semifinished products, the immediate consumption of the nonrenewable exergy extracted from nature, the TEC of the wear of machines and installations, and the TEC of compensation of losses that are due to the rejection of deleterious waste products.

The first system of the mentioned balance equations determining the total TEC reads:

$$
\begin{aligned}
\rho_{j}+\sum_{i}\left(f_{i j}-\right. & \left.a_{i j}\right) \rho_{i}-\sum_{r} a_{r j} \rho_{r} \\
& =\sum_{f} b_{f j}+\sum_{m} b_{m j}+\sum_{k} p_{k j} \zeta_{k}
\end{aligned}
$$

where:

$\rho_{j}, \rho_{i}, \rho_{r}$ - total value of the TEC of major product of the $j^{\text {th }}$ considered process, of the remaining processes belonging to the system and of the $r^{\text {th }}$ imported product;

$b_{f j}, b_{m j}$ - exergy of the fuel and of the mineral raw material immediately extracted from nature, per unit of the $j^{\text {th }}$ major product;

$a_{i j}, a_{r j}$ - coefficient of the consumption of the $i$ th domestic and $r$ th imported semi-finished product per unit of the $j^{\text {th }}$ major product;

$f_{u j}$ - coefficient of production of the $u$ th byproduct per unit of the $j^{\text {th }}$ major product;

$p_{k j}$ - coefficient of the production of the $k$ th rejected waste product per unit of the $j^{\text {th }}$ major product;

$\zeta_{k}$ - total TEC of compensation of the deleterious impact of the $k^{\text {th }}$ rejected waste product.

The values of $\rho_{j}, \rho_{i}$ are unknown in the first equation system. The second system of balance equations independent from the first one determines the fuel part of TEC:

$$
\begin{gathered}
z_{j} \rho_{j}+\sum_{i}\left(f_{i j}-a_{i j}\right) z_{i} \rho_{i}-\sum_{r} a_{r j} z_{r} \rho_{r} \\
=\sum_{f} b_{f j}+\sum_{k} p_{k j} z_{k} \zeta_{k}
\end{gathered}
$$

where:

$z_{j}, z_{i}, z_{r}, z_{k}-$ the fraction of fuel part of the considered quantity.

The values of $z_{j}, z_{i}$ are unknown in the second equation systems. In Eqs. (1) and (2) the components with $b_{f}, b_{m}$ appear only when considering the mines extracting raw materials from nature.

The TEC of the imported materials results from the assumption that the financial means for the import are gained by export. Hence the values of TEC of imported materials results from their monetary cost and from the mean TEC-value of the monetary unit of export:

$\rho_{r}=\frac{\sum_{e} S_{e} \rho_{e}}{\sum_{i} S_{e} D_{e}} D_{r}=D_{r} \rho_{m}$

where:

$D_{r}, D_{e}-$ monetary cost per unit of the imported and exported product;

$S_{e}, \rho_{e}$ - number of units of the annual export of the $e^{\text {th }}$ product and its index of the total TEC;

$\rho_{m}$ - mean value of the total TEC per monetary unit of export.

The so determined values of TEC of the imported materials should be divided into the fuel part and mineral part using the proportions appearing in the domestic production:

$\rho_{r} z_{r}=D_{r} \frac{\sum_{e} S_{e} z_{e} \rho_{e}}{\sum_{e} S_{e} D_{e}}=D_{r} \rho_{m} z_{r}$

where:

$z_{e}-$ fraction of the fuel part of TEC of exported products.

The values of $z_{e}$, and $\rho_{e}$ can be determined by means of a difficult iterative method.

When considering electricity produced from renewable resources, the fuel part and mineral part of TEC of the used operational and investment means should be taken into account.

\section{Example 1}

A simplified system presented in Fig. 1 is considered. The system comprises a coal mine 1 , an iron ore mine 2 , a power plant 3 fed with coal, steel works (with coke plant) 4 , and a natural gas mine 5 extracting gas from a domestic resource. Some amount of natural gas is imported and consumed in the steelworks.

The consumption coefficients shown in Fig. 1 take into account only the time of normal operation and express:

- in the coal mine: electricity and steel products;

- in the iron ore mine: electricity and coal;

- in the power plant: hard coal;

- in the steel works: coal, iron ore, electricity, domestic natural gas and imported natural gas;

- in the mine of natural gas: electricity.

The immediate depletion $b_{j}$ of domestic natural resources comprises the chemical exergy of hard coal and of natural gas (fuel part) and chemical exergy of iron ore (belonging to the mineral part).

The considered waste products are $\mathrm{SO}_{2}, \mathrm{NO}_{\mathrm{x}}$ and dust. The quantity $\zeta_{k}$ in Eq. (1) appears only with the consumption of coal. The assumed values of $\zeta_{k}, z_{k}$ of the mentioned waste products are $\zeta_{1}=\zeta_{\mathrm{SO} 2}=108.0 ; \zeta_{2}=\zeta_{\mathrm{NOx}}=79.0 ; \zeta 3=\zeta_{d}=59.0$ $\mathrm{MJ} / \mathrm{kg}$, and $z_{k}=0.99$.

The value of TEC of imported natural gas results from the assumption of exported domestic products (coal and steel products in the mass proportion $4: 1$ ). The sell price of coal is $0.15 \mathrm{EUR} / \mathrm{kg}$ and of steel products $0.75 \mathrm{EUR} / \mathrm{kg}$. The purchase price of the imported natural gas is $0.01 \mathrm{EUR} / \mathrm{MJ}$. Application of Eqs (3) and (4) requires an iterative procedure because the production of steel is also burdened with the consumption of imported natural with the TEC depending on the consumption of coal in the steel production. 
Balance Boundary

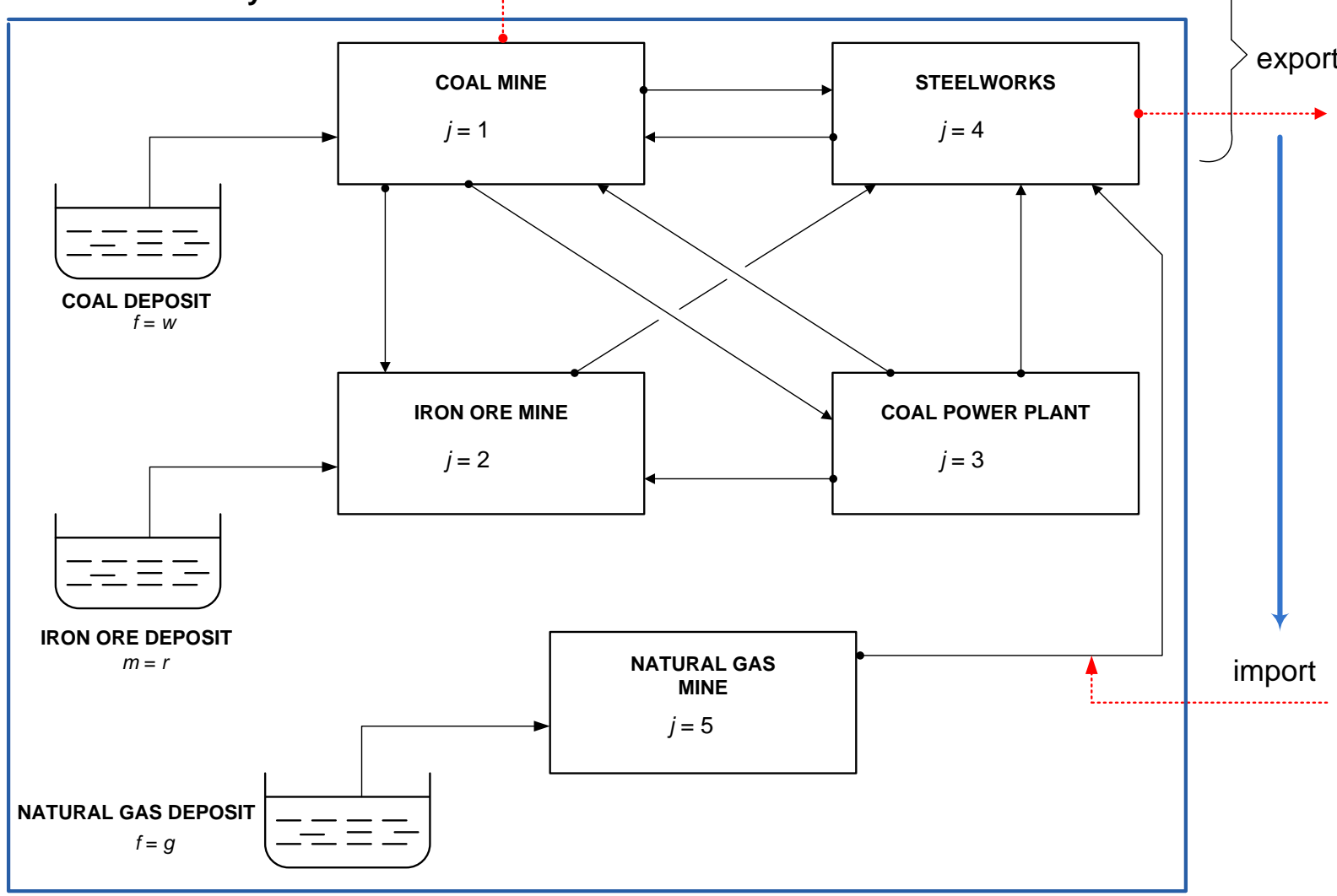

Figure 1. Simplified production system.

Table 1. Data and calculation results in the Example 1.

\begin{tabular}{|c|c|c|c|c|c|c|}
\hline & & \multicolumn{5}{|c|}{ Considered $j$ th process } \\
\hline & & 1 & 2 & 3 & 4 & 5 \\
\hline & & $\mathrm{kg}$ & $\mathrm{kg}$ & $\mathrm{MJ}$ & $\mathrm{kg}$ & $\mathrm{kmol}$ \\
\hline \multirow{6}{*}{$\begin{array}{c}\text { Consumed } \\
i \text { th product } \\
a_{i j} \\
{[\mathrm{i}] /[\mathrm{j}]}\end{array}$} & $i=1$ & - & 0.001 & 0.137 & 0.410 & - \\
\hline & 2 & - & - & - & 1.340 & - \\
\hline & 3 & 0.240 & 0.094 & - & 2.000 & 4.170 \\
\hline & 4 & 0.120 & - & - & - & - \\
\hline & 5 & - & - & - & 0.002 & - \\
\hline & $5 r$ & - & - & - & 0.005 & - \\
\hline \multirow{3}{*}{$\begin{array}{c}p_{k j} \\
\mathrm{~kg} /[\mathrm{j}]\end{array}$} & $k=1$ & 0.0001 & 0.0002 & 0.001 & 0.0004 & 0.0000 \\
\hline & 2 & 0.0001 & 0.0002 & 0.002 & 0.0001 & 0.0000 \\
\hline & 3 & 0.0001 & 0.0002 & 0.003 & 0.0006 & 0.0000 \\
\hline \multicolumn{2}{|c|}{$\begin{array}{c}b_{j} \\
\mathrm{MJ} /[\mathrm{j}]\end{array}$} & 26.16 & 0.80 & 0.00 & 0.00 & 809.43 \\
\hline \multicolumn{2}{|c|}{$\begin{array}{c}\rho_{j} \\
\mathrm{MJ} /[\mathrm{j}]\end{array}$} & 30.96 & 1.33 & 4.78 & 30.23 & 829.36 \\
\hline \multicolumn{2}{|c|}{$r_{j}$} & 1.18 & 1.66 & 4.78 & & 1.03 \\
\hline \multicolumn{2}{|c|}{$\begin{array}{l}z_{j} \\
\%\end{array}$} & 99.49 & 37.82 & 99.54 & 95.81 & 99.99 \\
\hline
\end{tabular}

The symbols [j], [i] denote the unit of $j^{\text {th }}$ and $i^{\text {th }}$ product. 
The calculated values of discussed quantities are cited in Table 1. The values of the fuel part of TEC dominates in the case of all considered major products with exception of iron ore manifesting the fraction 0.6 of mineral part.

\section{Example 2}

Example 2 relates to the Polish energy and technology system and bases upon the data of 2008 year. The data characterizing the export are cited in Table 2.

Table 2. Structure of the Polish export in year 2008

\begin{tabular}{|c|c|c|c|}
\hline \multirow[b]{2}{*}{ No. } & & \multicolumn{2}{|l|}{$\mathrm{S}_{\mathrm{e}}$} \\
\hline & $\begin{array}{l}\text { Fuel/ semi-finished } \\
\text { products/ finished } \\
\text { products }\end{array}$ & $\mathrm{kt}$ & $\operatorname{mln} €$ \\
\hline 1 & Coke & 6118 & 1701 \\
\hline 2 & Hard coal & 8500 & 955 \\
\hline 3 & Steel blocks & 4263 & 4283 \\
\hline 4 & Cooper & 436 & 2058 \\
\hline 5 & Steel products & 1479 & 591 \\
\hline 6 & Aluminum & 479 & 1465 \\
\hline 7 & Machines \& devices & 605 & 4469 \\
\hline 8 & $\begin{array}{l}\text { Agricultural products - } \\
\text { meat }\end{array}$ & 1222 & 2368 \\
\hline 9 & $\begin{array}{l}\text { Agricultural products - } \\
\text { vegetable }\end{array}$ & 2863 & 2553 \\
\hline 10 & Paper & 1549 & 1214 \\
\hline 11 & Refinery products & 2670 & 1408 \\
\hline 12 & Fertilizer & 2403 & 758 \\
\hline 13 & Silver & 1 & 371 \\
\hline 14 & PCV & 1094 & 1137 \\
\hline 15 & Rubber products & 120 & 193 \\
\hline 16 & Glass & 499 & 465 \\
\hline 17 & Wood & 1434 & 450 \\
\hline 18 & Sulfur & 474 & 99 \\
\hline 19 & Cement & 589 & 54 \\
\hline
\end{tabular}

The high diversity of exported products compels the aggregation of similar products. The values cited in Table 2 determine the mean TEC and the mean fuel fraction of TEC per monetary unit of the sell price of exported products: $\rho_{m}=$ 52.0 MJ/Euro, and $z_{r}=0.99$. Table 3 contains the values of total TEC and of its fuel fraction characterizing the most important domestic industrial products.

Only in the case of sulfur and copper ore is the fuel fraction of TEC considerably smaller than $100 \%$.

\section{Conclusions}

The partition of the TEC into a fuel part and mineral part is purposeful because the depletion of mineral resources is more dangerous for the future economy of humankind. Any renewable mineral resources do not exist. The destructed rich mineral resources may be replaced only by the more lean ones requiring a higher consumption of exergy in their utilization process. Fortunately the fraction of mineral part of the TEC is usually very small, it is remarkable only in the case of immediate products of the mines of minerals. It is worth stressing, the chemical exergy of natural fuels can be calculated with sufficient accuracy, whereas the chemical exergy of minerals can be only approximately estimated.

\section{Acknowledgments}

The paper has been prepared within the RECENT project (REsearch Center for Energy and New Technologies) supported by 7 th Framework Programme, Theme 4, Capacities.

Table 3. TEC of selected product

\begin{tabular}{|r|l|r|r|}
\hline No. & Product & $\begin{array}{c}\text { TEC } \\
\mathrm{MJ} / \mathrm{j}]\end{array}$ & \multicolumn{1}{c|}{$z_{j}$} \\
\hline 1 & Coking coal & 31.20 & 1.000 \\
\hline 2 & Natural gas & 835.86 & 1.000 \\
\hline 3 & Electricity & 3.42 & 1.000 \\
\hline 4 & Coke & 47.44 & 1.000 \\
\hline 5 & Sinter & 5.95 & 0.997 \\
\hline 6 & Pig iron & 30.46 & 0.999 \\
\hline 7 & Hard coal & 27.08 & 1.000 \\
\hline 8 & Oxygen & 156.41 & 1.000 \\
\hline 9 & Lime & 8.38 & 0.981 \\
\hline 10 & BOF steel & 27.40 & 0.999 \\
\hline 11 & EAF steel & 12.12 & 0.999 \\
\hline 12 & Metallurgical products & 27.16 & 0.999 \\
\hline 13 & Sulphur & 24.60 & 0.223 \\
\hline 14 & Copper ore & 0.97 & 0.382 \\
\hline 15 & Copper & 169.48 & 0.987 \\
\hline 16 & Cement & 5.91 & 0.959 \\
\hline 17 & Copper products & 193.77 & 0.999 \\
\hline 18 & Machines and devices & & \\
\hline
\end{tabular}

\section{References}

Cornellisen R.L., Nimwegen P.A. van \& Hirs G.G. (2000). Exergetic Life-Cycle Analysis. Proceedings ECOS 2000, Enshede, The Netherlands.

El-Sayed Y. M. \& Aplenc A. J. (1970). Application of the Thermoeconomic Approach to the Analysis and Optimization to the Vapour-Compression Desalting System. J. Eng. Power 92(1), 17-26.

El-Sayed Y. M. \& Evans R. B. (1970). Themoeconomics and the Design of Heat Systems. J. Eng. Power 92(1), 27- 35.

Stanek W. (2009). Evaluation Method of the Ecological Effects in Thermal Processes Using the Exergy Analysis (in Polish), Edition of the Silesian University of Technology, Gliwice.

Szargut J. (1978). Minimization of the Consumption of Natural Resources. Bull. Pol. Acad. Sci. ser. Techn. 6, 4145.

Szargut J. (1986). Application of Exergy for the Calculation of Ecological Cost. Bull. Pol. Acad. Sci. ser. Techn. 7-8, 475-480.

Szargut J. (1997). Depletion of Unrestorable Natural Exergy Resources. Bull. Pol. Acad. Sci. ser. Techn. 2, 241-259.

Szargut J. (2004). Optimization of the Design Parameters Aiming at the Minimization of the Depletion of Non-renewable Resources. Energy, the Intern. Journ. 2161- 2169. 